\title{
VIRTUAL REALITY MUSEUM SUNAN DRAJAT LAMONGAN BERBASIS RULE- BASED SYSTEM UNTUK PEMBELAJARAN SEJARAH
}

\author{
Ari Kusumaningsih ${ }^{1}$, Cucun Very Angkoso² ${ }^{2}$ Novian Anggraeny $^{3}$ \\ 1,2,3 Teknik Informatika, Fakultas Teknik, Universitas Trunojoyo Madura \\ Email: ${ }^{1}$ ari.kusumaningsih@trunojoyo.ac.id, ${ }^{2}$ cucunvery@trunojoyo.ac.id, ${ }^{3}$ anggraenynovian1327@gmail.com
}

(Naskah masuk: 23 Mei 2018, diterima untuk diterbitkan: 23 September 2018)

\begin{abstract}
Abstrak
Perkembangan peradaban suatu bangsa dapat dilihat melalui museum yang dimilikinya. Dalam hal upaya untuk mencerdaskan masyarakat, museum diwajibkan selalu kreatif dalam menarik minat pengunjung, sehingga tujuan pendirian museum tetap terlaksana. Antusias masyarakat dalam menjelajahi museum saat ini semakin menurun, sehingga museum perlu melakukan inovasi agar tetap mampu menarik minat masyarakat untuk berkunjung. Pada penelitian ini berhasil dibuat aplikasi Virtual Reality (VR) Museum Sunan Drajat berbasis Android dalam memudahkan seseorang untuk belajar sejarah yang mampu membawa pengguna ke dalam dunia maya dengan merasakan sensasi nyata mengunjungi museum, dengan menerapkan metode Rule-Based System (RBS) sebagai desain skenario sistem dalam penjelajahan museum. Diharapkan setelah menggunakan aplikasi ini, museum dapat menarik perhatian masyarakat sehingga kembali tertarik untuk mempelajari sejarah bangsanya. Dari hasil pengujian aplikasi diketahui bahwa $95.8 \%$ responden sangat setuju bahwa aplikasi ini dapat dijadikan sebagai pembelajaran sejarah. Berdasarkan hasil uji keefektifan aplikasi rata-rata nilai Report Score yang diperoleh pada menu evaluation yaitu 92\% yang berarti aplikasi VR Museum Sunan Drajat sangat efektif digunakan sebagai pembelajaran sejarah.
\end{abstract}

Kata kunci: Museum Sunan Drajat, Virtual Reality, Rule-Based System.

\section{VIRTUAL REALITY MUSEUM SUNAN DRAJAT LAMONGAN BASED ON RULE- BASED SYSTEM FOR HISTORICAL LEARNING}

\begin{abstract}
Historical journey of the nation's civilization can be seen through their museum. In terms of efforts to educate the public, the museum is always required to be creative in attracting visitors so that the purpose of establishment of the museum is still carried out. The enthusiasm of people in exploring the museum is now declining so that the museum need to innovate in order to remain able to attract the public interest to visit. In this research, the application of Virtual Reality (VR) Museum Sunan Drajat based on Android in facilitating someone to learn history that can bring users into the virtual world by feeling the real sensation of visiting the museum, by applying Rule-Based System(RBS) method as a system scenario design in museum exploration. It is hoped that after using this application, it can attract the public's attention so that it is interested to learn about the history of the nation. From the results of application testing known that $95.8 \%$ of respondents strongly agree that this application can be used as a learning history. Based on the results of test effectiveness of the average application score Report Score obtained on the evaluation menu is $92 \%$ which means the application VR Museum Sunan Drajat very effectively used as a learning history.
\end{abstract}

Keywords: Museum Sunan Drajat, Virtual Reality, Rule-Based System.

\section{PENDAHULUAN}

Peradaban suatu bangsa dapat dipelajari melalui sejarah yang melatarbelakanginya. Museum adalah sarana efektif untuk belajar sejarah dan peradaban. Namun, antusiasme masyarakat dalam menjelajahi museum saat ini semakin menurun, sehingga museum perlu melakukan inovasi agar tujuan pendirian museum sebagai sarana pendidikan sejarah bagi masyarakat tetap terlaksana. Disisi lain, perkembangan teknologi mobile Android dan aplikasinya, sangat menarik perhatian masyarakat saat ini. Kebutuhan akan aplikasi Android yang positif dan mendidik semakin meningkat. Melalui teknologi Virtual Reality (VR) ini memungkinkan masyarakat mendapatkan pengalaman mengujungi 
pameran benda bersejarah dengan cara berbeda. Pada penelitian yang dilakukan oleh Wojciechowski telah berhasil membangun sebuah aplikasi virtual museum berbasis web-desktop dengan tambahan fitur Augmented Reality (Wojciechowski, Walczak, White \& Cellary, 2004). Adapun penerapan teknologi 3Dimensi (3D) VR untuk pembelajaran sejarah, pernah dilakukan pada aplikasi 3D viewer mobile peristiwa sejarah perobekan bendera Belanda di hotel Majapahit (Sihite, Samopa \& Sani, 2013). Aplikasi berbasis VR sudah banyak dijumpai, termasuk juga yang diterapkan pada desain museum virtual namun belum ada yang mengangkat obyek museum di Indonesia. Pada penelitian ini berhasil menerapkan aplikasi VR 3D untuk pembelajaran sejarah di Indonesia, melalui aplikasi VR 3D Museum Sunan Drajat berbasis mobile Android. Pada penelitian ini menggunakan metode Rule-Based System (RBS) dan metode pengembangan aplikasi multimedia interaktif. Desain skenario sistem VR dalam penjelajahan museum menggunakan metode RBS agar terstruktur dengan baik sehingga meminimalisasikan error/bug yang terjadi karena semua rule telah didefinisikan dengan jelas. Penggabungan metode RBS dan metode desain multimedia interaktif untuk pengembagan aplikasi VR-Museum selama ini belum ditemukan pada artikel ilmiah yang terpublikasi. Di bagian akhir penelitian ini telah dilakukan metode survey dan juga perencangan mini-quiz berbasis VR untuk mendapatkan jawaban rumusan masalah apakah aplikasi VR-museum ini efektif digunakan untuk pembelajaran sejarah. Aplikasi VR-Museum Sunan Drajad ini akan membawa pengguna merasa masuk ke dalam dunia maya museum dan mengenal berbagai bentuk alat musik tradisional koleksi museum Sunan Drajat beserta suaranya, sehingga pengguna merasakan sensasi nyata mengunjungi museum secara langsung.

\subsection{Museum Sunan Drajat}

Museum yang digunakan sebagi penelitian yaitu Museum Sunan Drajat yang terletak di Desa Drajat Kecamatan Paciran Lamongan Jawa Timur. Untuk menghormati jasa-jasa Sunan Drajat sebagai seorang Wali penyebar agama Islam di wilayah Lamongan dan untuk melestarikan budaya serta benda-benda bersejarah peninggalannya Sunan Drajat, keluarga dan para sahabatnya. Museum ini didirikan oleh pemerintah kabupaten pada tahun 1991, namun baru baru difungsikan pada 30 Maret 1992. Pada Museum terdapat koleksi batu, koin, fosil, keramik, pusaka, alat musik, fragmen unsur masjid, kain, kulit, perabotan dan bedhug (Anis, 2016).

\subsection{Kebutuhan Perangkat Pendukung Pada Virtual Reality}

Virtual Reality (VR) atau biasa disebut dengan realitas maya merupakan sebuah teknologi yang membuat pengguna bisa berinteraksi dengan lingkungan dan disimulasikan oleh komputer. Realitas maya dari suatu lingkungan umumnya disajikan sebagai pengalaman visual, yang ditampilkan pada sebuah layar komputer atau melalui sebuah stereokopik (Wojciechowski, Walczak, White \& Cellary, 2004). Dalam VR diperlukan sebuah alat pendukung untuk merealisasikan Objek 3D yaitu Google Cardboard dengan menggunakan Smartphone Android. Google cardboard merupakan temuan Google yang memungkinkan seseorang mengalami realitas virtual secara sederhana, menyenangkan, dan cara yang terjangkau. Kerja Google cardboard didukung dengan hampir semua smartphone Android atau iOS.

Pengembangan aplikasi VR ini diterapkan untuk perangkat bergerak (ponsel pintar) dengan sistem operasi android. Adapun syarat minimum yang dibutuhkan pada hardware ponsel pintar tersebut harus tersedia beberapa sensor native seperti pada Gambar 1.

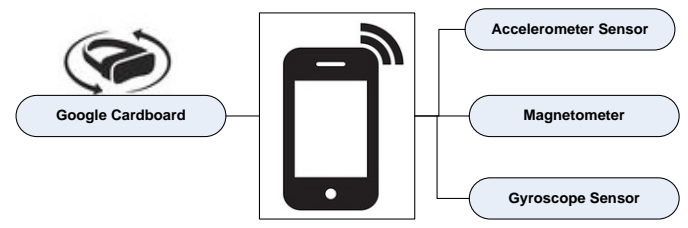

Gambar 1. Kebutuhan dasar sistem VR pada Android Smartphone.

\subsubsection{Accelerometer Sensor}

Accelerometer adalah sensor yang digunakan untuk mengukur percepatan suatu objek, yakni mengukur percepatan dinamis dan statis. Pengukuran dinamis adalah pengukuran percepatan pada objek bergerak, sedangkan pengukuran statis adalah pengukuran terhadap gravitasi bumi. Contoh penggunaan sensor ini yaitu ketika kita memutar smartphone dari portrait ke modus landscape. Sensor Accelerometer saat ini, umumnya telah tersedia di hampir semua smartphone yang ada di pasaran.

\subsubsection{Magnetometer}

Magnetometer yang dikenal dengan sensor kompas ini digunakan untuk mengetahui arah dari smartphone terhadap medan magnet bumi. Fungsi sensor ini bertugas untuk menentukan arah berupa sebuah panah penunjuk magnetis yang bebas menyelaraskan dirinya dengan medan magnet bumi secara akurat.

\subsubsection{Sensor Gyroscope}

Gyroscope atau Gyro berfungsi untuk mengukur atau mempertahankan orientasi dengan prinsip ketetapan momentum sudut. Mekanismenya adalah sebuah roda berputar dengan piringan di dalamya yang tetap stabil. Gyro digunakan untuk memeriksa kemiringan atau memutar gerakan dari smartphone. 
Gyroscope merupakan perangkat untuk mengukur atau mempertahankan orientasi gerak, yang berlandaskan pada prinsip-prinsip momentum sudut. Gyroscope merupakan sensor yang bisa mendeteksi pergeseran 3 sumbu X, Y, Z. Dalam Smartphone, Gyroscope sering dikombinasikan dengan Accelerometer untuk memperkuat motionsensing. Dari kombinasi tersebut didapatkan 6 sumbu pendeteksian yaitu 3 sumbu rotasi $(\mathrm{x}, \mathrm{y}, \mathrm{z})$ dan 3 sumbu linier (atas-bawah, kanan-kiri, depanbelakang). Gyroscope pada Smartphone dibenamkan menggunakan MEMS (Micro-electromechanical system) dapat mendeteksi gerakan sesuai gravitasi (gerakan pengguna). Hal ini memungkinkan smartphone untuk mengukur dan mempertahankan orientasi, arah, gerak, sudut dan rotasi. Pada teknologi VR, Sensor Gyroscope digunakan untuk mendeteksi gerakan kepala Player sehingga arah pandangan sesuai dengan apa yang ditampilkan oleh VR.

\section{METODE USULAN}

Pada penelitian ini menggunakan metode RBS dan metode pengembangan aplikasi multimedia interaktif, seperti yang ditampilkan pada Gambar 2. Metode desain sistem aplikasi multimedia interaktif (Dastbaz, 2002) dengan mengimplementasikan metode RBS pada bagian system-definition yaitu pada sub-bagian dari System Requirement (Arif, 2011), (Nastiti, 2016). Dengan pengaplikasian metode RBS dan metode pengembangan aplikasi multimedia interaktif telah didapatkan hasil sebuah aplikasi VRMuseum Sunan Drajad. Lebih lanjut, dengan efektifitas metode yang telah dipilih dalam proses pembelajaran sejarah akan ditunjukkan pada bagian akhir penelitian ini.

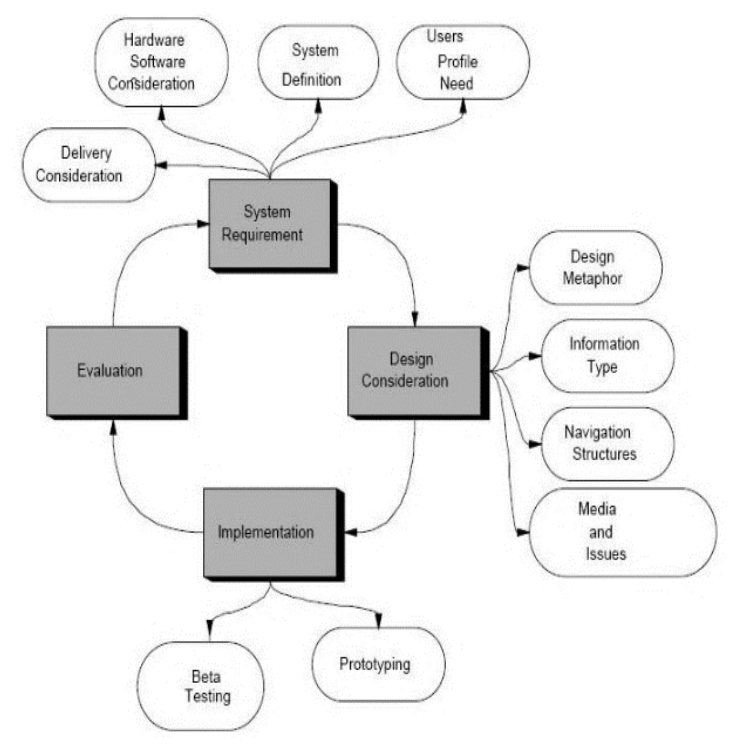

Gambar 2. Diagram desain pengembangan multimedia interaktif. (Dastbaz, 2002)

\subsection{Kebutuhan Sistem (System Requirement)}

Pada tahap ini suatu definisi umum dari IMS (Interactive Multimedia System) dan lingkungannya ditentukan. Tahap ini berfungsi untuk:

1. User profile needed. Menentukan sasaran pengguna. Pengguna aplikasi multimedia VR museum Sunan Drajat Lamongan ini adalah pelajar dan masyarakat umum.

2. System definition. Menentukan tujuan sebuah sistem multimedia akan dibuat. Aplikasi multimedia VR museum Sunan Drajat Lamongan ini bertujuan mengenalkan pengalaman baru kepada pengguna, berupa penjelajahan museum menggunakan VR serta sebagai alternatif media pembelajaran sejarah.

3. Hardware \& Software consideration. Pertimbangan perangkat keras dan lunak. Aplikasi multimedia VR museum Sunan Drajat Lamongan ini membutuhkan perangkat berupa google cardboard dan smartphone android yang memiliki sensor Accelerometer, magnetometer dan gyroscope.

4. Delivery consideration. Pertimbangan pengiriman (data). Aplikasi multimedia VR museum Sunan Drajat Lamongan ini merupakan aplikasi offline atau tidak membutuhkan koneksi jaringan data, ketika sedang digunakan.

\subsection{Pertimbangan Desain (Design Consideration)}

Pada tahap ini, terdapat 4 hal yang menjadi perhatian, yakni:

1. Design Metaphore. Metafora desain aplikasi multimedia VR museum Sunan Drajat Lamongan ini mengacu pada penelitian sebelumnya, pada museum Cakraningrat Bangkalan.

2. Information Type. Tipe informasi yang digunakan pada aplikasi multimedia VR museum Sunan Drajat Lamongan ini berupa data text, suara dan Gambar 3D.

3. Navigation Structure. Struktur navigasi aplikasi multimedia VR museum Sunan Drajat Lamongan ini menggunakan button yang tersedia pada google cardboard.

4. Media and issues. Aplikasi multimedia VR museum Sunan Drajat Lamongan ini berukuran $75 \mathrm{MB}$, dijalankan secara offline dan tidak terhubung ke media sosial.

Adapun tahap implementasi dan evaluasi akan disampaikan pada bagian selanjutnya.

\section{METODOLOGI PENELITIAN}

\subsection{Rule-Based System (Sistem Berbasis Aturan)}

RBS merupakan suatu sistem pakar dengan menggunakan beberapa aturan dalam menyelesaikan masalah yang dihadapi. Metode RBS ini dimulai dengan dasar aturan dari permasalahan yang ada kemudian dalam menghadapi masalah yang ada dengan dikodekan ke dalam aturan IF-THEN . Sistem 
memeriksa semua aturan kondisi IF yang menentukan subset permasalahan yang ada, jika ditemukan maka sistem melakukan kondisi THEN (F. Hayes-Roth, 1985). Looping akan terus berlanjut jika kondisi belum bertemu, jika salah satu/dua kondisi bertemu looping berhenti. Jika aturan tidak ditemukan maka sistem harus terminate (keluar dari looping).

Pada RBS, aturan-aturan untuk menyelesaikan masalah memiliki dua pendekat]an yaitu Forward Chaining (runut maju) disebut juga data driven dan Backward Chaining (runut balik) disebut juga goal driven (Arif, 2011), (Nastiti, 2016). Pada penelitan ini menggunakan metode RBS dengan pendekatan Forward Chaining (runut maju) disebut juga data driven sebagai desain skenario sistem VR dalam penjelajahan Museum.

\subsection{Penerapan Metode Rule-Based System}

Desain skenario sistem VR dalam penjelajahan Museum ini menggunakan metode RBS. Dalam proses penjelajahan museum Sunan Drajad menggunakan 2 mode yaitu mode mode Explore dan mode Evaluation. Diagram rule kedua mode tersebut tampak pada Gambar 3 dan 4.

Pada mode explore langsung keluar tampilan gedung Museum Sunan Drajat. Kamera akan berjalan secara otomatis sehingga seolah-olah berjalan dan melakukan penjelajahan Museum. Interaksi aktor menggunakan capacitive-button (toggle) pada Google Cardboard untuk melangkah maju dan berhenti. Saat berjalan dan di depan tidak ada halangan maka aktor berjalan lurus. Saat ada halangan, langsung belok kanan atau kiri dalam kondisi diam juga dapat berputar $360^{\circ}$, mendangak dan menunduk. Ketika koleksi Museum berupa alat musik tersentuh akan tampil deskripsi dan terdengar bunyi musik, selain alat musik maka tampil deskripsi. Cara keluar dari Mode ini yaitu dengan tombol home yang langsung diarahkan ke pilihan menu, untuk keluar dari aplikasi dengan tombol exit yang ada pada pilihan menu.

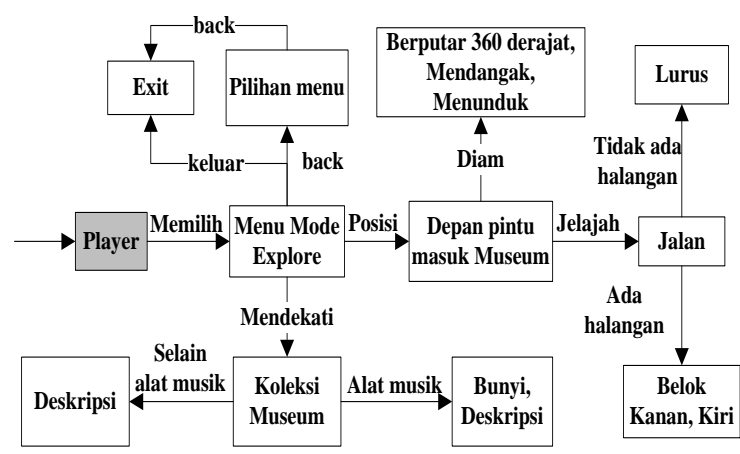

Gambar 3. Diagram rule pada Mode Explore

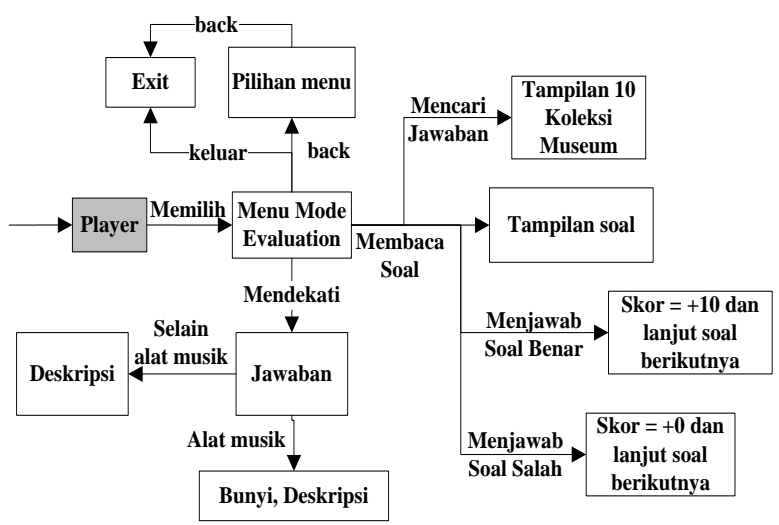

Gambar 4. Diagram rule Mode Evaluation

Selanjutnya pada Gambar 5 menjelaskan tentang alur VR Museum Sunan Drajat berjalan. Adapun penjelasannya sebagai berikut:

1. Tampilan awal aplikasi berupa petunjuk untuk memilih home yang mengarah ke tampilan menu, menu-menu yang tersedia diantaranya yaitu direction, explore, dan evaluation.

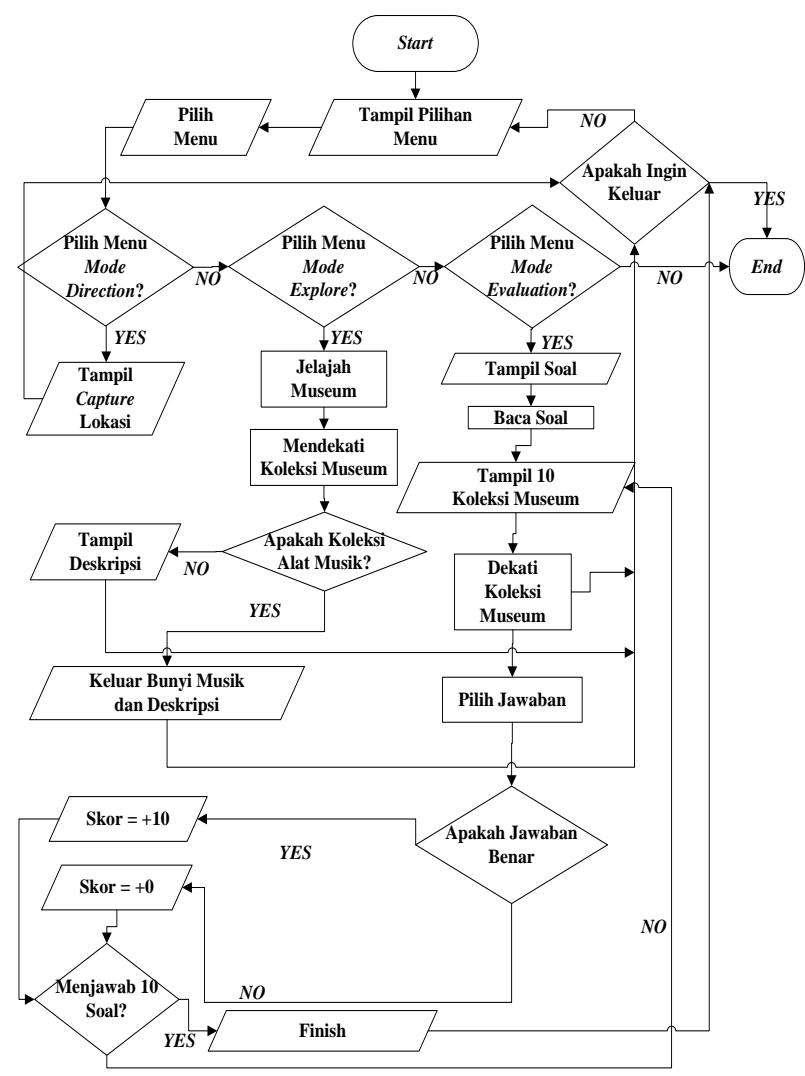

Gambar 5. Flowchart Virtual Reality

2. Pada menu direction map langsung keluar tampilan capture lokasi Museum Sunan Drajat. Selesai menampilkan semua capture map, cara keluar dari Mode ini yaitu dengan tombol home yang langsung diarahkan ke pilihan menu, untuk 
keluar dari aplikasi dengan tombol exit pada pilihan menu.

3. Pada menu explore langsung keluar tampilan gedung Museum Sunan Drajat. Kamera akan berjalan secara otomatis sehingga seolah-olah berjalan untuk jelajah Museum. Ketika koleksi museum berupa alat musik tersentuh maka akan tampil deskripsi dan terdengar bunyi musik, selain alat musik maka tampil deskripsi. Cara keluar dari Mode ini yaitu dengan tombol home yang langsung diarahkan ke pilihan menu, untuk keluar dari aplikasi dengan tombol exit pada pilihan menu.

4. Pada menu evaluation langsung keluar tampilan soal pada depan pintu masuk gedung museum dan terdapat 10 koleksi museum di dalam gedung, soal berupa pertanyaan tentang nama-nama koleksi museum. Menjawab soal dengan benar skor $=+10$ dan jika salah skor $=+0$ dan lanjut soal berikutnya. Sepuluh soal sudah terjawab tampil total skor akhir dan langsung diarahkan ke pilihan menu, untuk keluar dari aplikasi dengan tombol exit ada pada pilihan menu.

\subsection{Implementasi Pembuatan Objek 3D Museum Sunan Drajat}

Dalam membangun obyek 3D pada Skripsi ini menggunakan perangkat lunak Blender 2.78. Adapun tahapan dalam pembuatan obyek 3D yaitu:

a) Pengukuran. Pada tahap ini dilakukan pengukuran dimensi terhadap obyek-obyek yang akan dibuat model 3Dnya. Pengukuran dilakukan agar model 3D yang dibuat terlihat lebih realistis dengan menjaga bentuk proposionalnya.

b) Pemodelan 3D. Pada tahap ini dilakukan pembuatan model obyek 3D yang ada di di dalam dan di sekitar Museum Sunan Drajat seperti gedung, pintu, jendela, koleksi museum, dan obyek 3D yang lainnya menggunakan perangkat lunak Blender.

Pada pengolah 3D Blender yang pertama kali dilakukan adalah membuat model gedung Museum Sunan Drajat sesuai dengan bentuk aslinya dan disesuaikan dengan dimensi berdasarkan pengukuran yang telah dilakukan agar model 3D yang dibuat terlihat lebih realistis dengan menjaga bentuk proposionalnya. Seperti pada Gambar 6.

Selanjutnya yaitu membuat konten-konten 3D yang terdapat dalam lingkungan gedung Museum yaitu koleksi Museum, lemari, meja, dan Obyek 3D yang lainnya. Agar dapat menghasilkan bentuk yang proporsional dibutuhkan proses pengukuran panjang, lebar dan tinggi terhadap masing-masing obyek. Seperti pada Gambar 7.

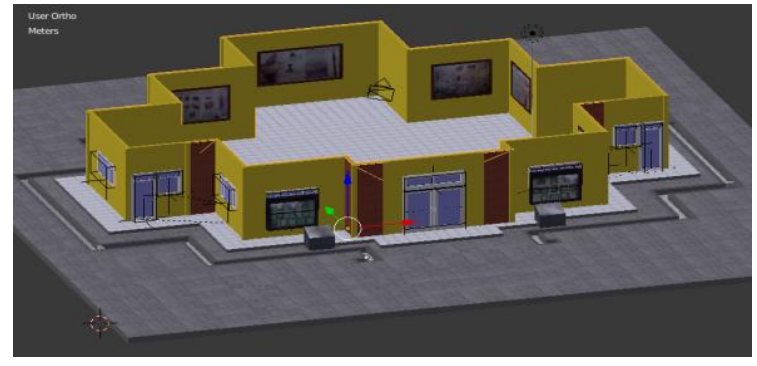

Gambar 6. Proses pemodelan obyek 3D gedung Museum Sunan

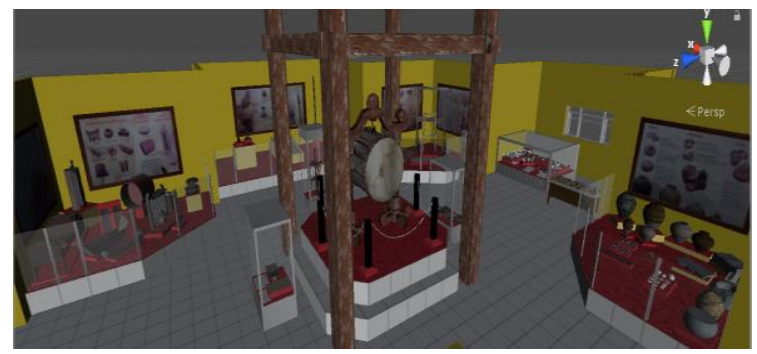

Gambar 7. Pemodelan konten-konten 3D

\subsection{Implementasi Desain Gedung Museum}

Setelah selesai mengimport semua aset, menata obyek-obyek 3D kedalam scene window sehingga menyerupai susunan obyek dalam Museum Sunan Drajat seperti pada Gambar 8.

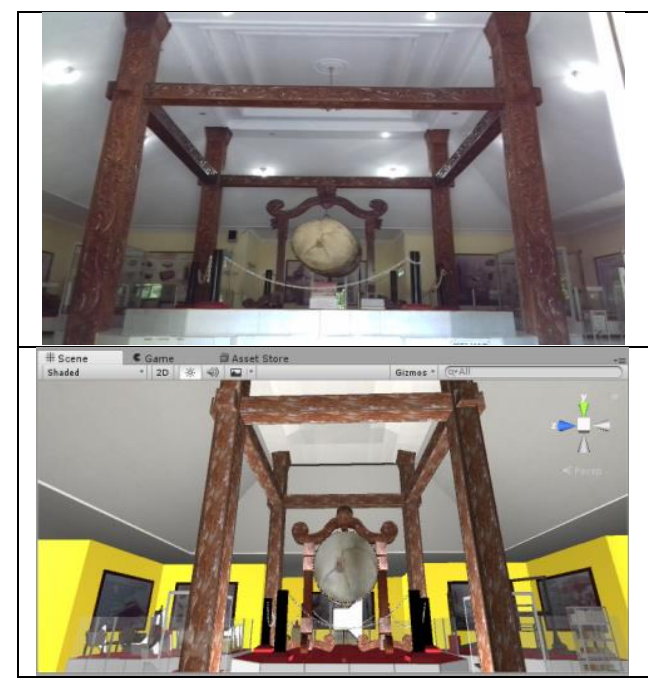

Gambar 8. Kondisi nyata vs obyek 3D lingkungan museum Sunan Drajat

\subsection{Implementasi Interface Aplikasi}

Tampilan main menu dapat dilihat pada Gambar 9. pada main menu terdapat 3 menu utama, yaitu menu direction map, explore, evaluation, exit.

\section{a. Menu Exit}

Menu exit digunakan jika akan keluar dari aplikasi VR Museum. 


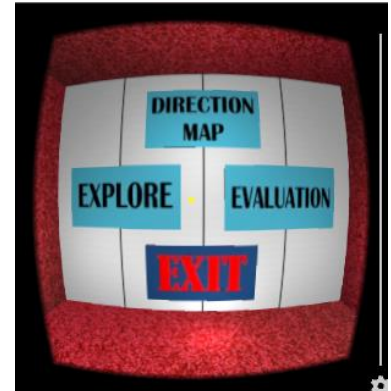

Gambar 9. Tampilan main menu

\section{b. Tombol Home}

Tombol home dapat digunakan ketika player ingin kembali ke menu utama. Seperti pada Gambar 10 dan 11.

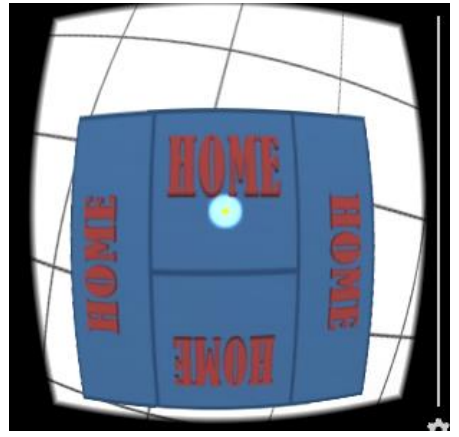

Gambar 10. Tombol home saat player menunduk

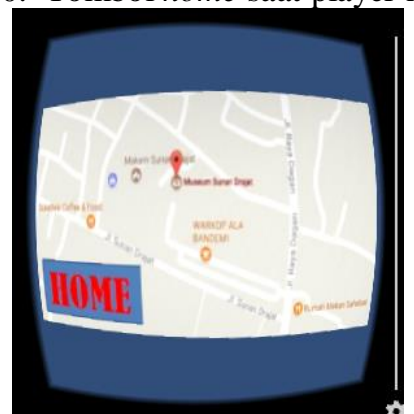

Gambar 11. Tampilan tombol home pada scene map

\subsection{Tampilan Virtual Reality Museum}

Pada menu explore tampilan VR Museum, seperti pada Gambar 12. Pada scene Museum ini player dapat bebas melakukan eksplorasi dan melihat-lihat koleksi Museum serta melihat deskripsi dari koleksi tersebut, sebagai pembelajaran sejarah.

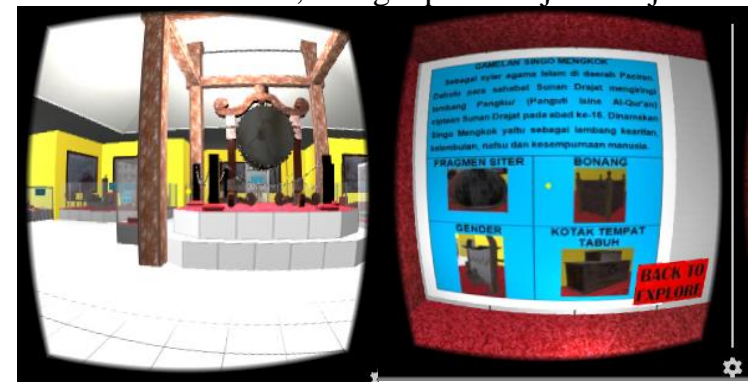

Gambar 12. Tampilan dalam gedung dan deskripsi

\section{c. Scene Evaluation}

Menu evaluation ini dibuat dengan tujuan sebagai evaluasi pemahaman player. Dengan range nilai 10-100, pada menu evaluation ini disediakan 10 pertanyaan berkaitan dengan koleksi Museum, masing-masing soal bernilai 10 jika jawaban benar, jika salah bernilai 0. Setelah 10 koleksi museum sudah dijawab maka akan tampil tulisan "FINISH!" dan langsung kembali ke menu home akan tetapi jika ingin kembali ke menu utama sebelum selesai, pada saat berdiri atau berjalan bisa dengan menunduk untuk menemukan menu home, tersebut.

Gambar 13, menunjukkan bahwa GazePointer untuk menjawab nama dari koleksi museum.

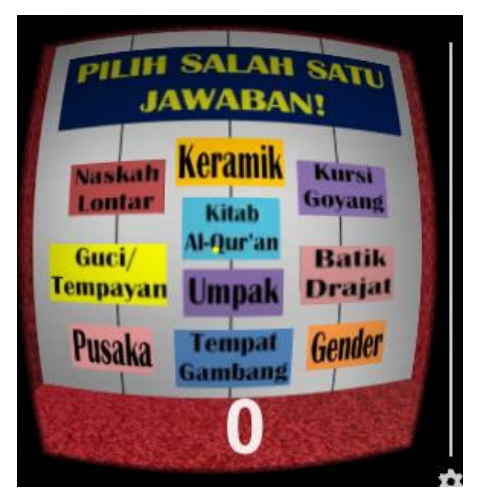

Gambar 13. Tampilan scene jawaban

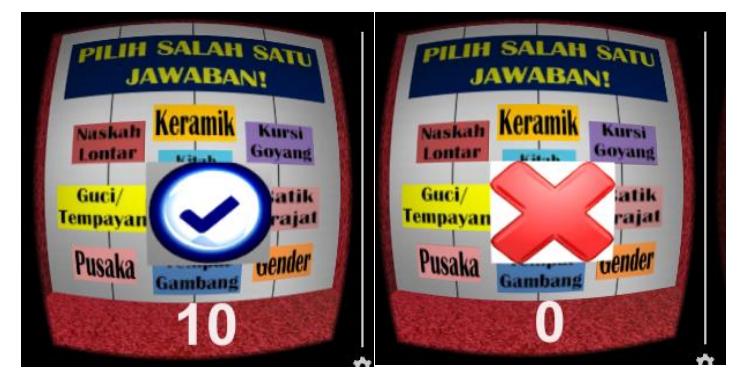

Gambar 14. Tampilan jika jawaban yang dipilih saat benar atau salah

Gambar 14. menunjukkan saat player menjawab dengan jawaban yang benar atau jika jawaban salah.

\section{HASIL DAN PEMBAHASAN}

\subsection{Pengujian Fungsionalitas}

Pengujian ini dilakukan untuk mengetahui apakah aplikasi yang dibuat sudah sesuai pada tahap perencanaannya. Dari ujicoba didapatkan solusi untuk mempercepat durasi loading aplikasi, yaitu dengan mengurangi jumlah verteks pada setiap obyek 3D dengan tetap tidak mengurangi kemiripan terhadap bentuk aslinya. Setelah dilakukan proses pengurangan vertex terhadap obyek 3D maka waktu yang diperlukan untuk proses loading sudah berkurang meskipun masih perlu ditingkatkan lagi.

Penggunaan metode RBS untuk memastikan tidak ada rule yang tidak/belum didefinisikan. Tujuan dari penggunaan metode ini yaitu untuk memastikan tidak terjadi error/bug yang belum di handle pada skenario yang direncanakan. Sehingga pengujian keberhasilan metode dilakukan dengan melakukan uji 
fungsionalitas semua fitur dan pengaplikasiannya pada 6 perangkat perangkat android yang berbeda.

Tabel 1 Uji fungsionalitas Fitur pada aplikasi Virtual Reality Museum Sunan Drajat

\begin{tabular}{|c|c|c|}
\hline Fitur & $\begin{array}{l}\text { Prosedur } \\
\text { Pengujian }\end{array}$ & Hasil Pengujian \\
\hline $\begin{array}{l}\text { Navigasi } \\
\text { Arah } \\
\text { (Jalan) }\end{array}$ & $\begin{array}{l}\text { Menjalankan } \\
\text { Aplikasi VR } \\
\text { Museum }\end{array}$ & $\begin{array}{l}\text { Berfun gsi } \\
\text { dengan baik, } \\
\text { ketika button } \\
\text { ditekan maka } \\
\text { player berjalan } \\
\text { dan pergerakan } \\
\text { player terhenti } \\
\text { jika ditekan lagi. }\end{array}$ \\
\hline $\begin{array}{l}\text { Suara } \\
\text { "Klik" }\end{array}$ & $\begin{array}{l}\text { Player } \\
\text { menekan salah } \\
\text { satu tombol } \\
\text { menu yang } \\
\text { ada di main } \\
\text { menu screen }\end{array}$ & $\begin{array}{l}\text { Berfungsi } \\
\text { dengan baik, } \\
\text { terdegar suara } \\
\text { "klik" pada saat } \\
\text { player menekan } \\
\text { tombol menu } \\
\text { yang ada di } \\
\text { main menu. }\end{array}$ \\
\hline $\begin{array}{l}\text { Suara } \\
\text { Backsound }\end{array}$ & $\begin{array}{l}\text { Menjalankan } \\
\text { Aplikasi VR }\end{array}$ & $\begin{array}{l}\text { Berfungsi } \\
\text { dengan baik, } \\
\text { terdengar suara } \\
\text { backsound saat } \\
\text { player berada di } \\
\text { main menu } \\
\text { hingga aplikasi } \\
\text { dikeluarkan } \\
\text { (exit). }\end{array}$ \\
\hline $\begin{array}{l}\text { Deteksi } \\
\text { Tumbukan } \\
\text { (Collision) }\end{array}$ & $\begin{array}{l}\text { Player } \\
\text { menyentuh } \\
\text { salah satu } \\
\text { obyek, dan } \\
\text { tidak dapat } \\
\text { menembus } \\
\text { obyek. }\end{array}$ & $\begin{array}{l}\text { Berfungsi } \\
\text { dengan baik, } \\
\text { terjadi } \\
\text { tumbukan pada } \\
\text { saat player } \\
\text { bersentuhan } \\
\text { dengan obyek } \\
\text { sehingga player } \\
\text { tidak dapat } \\
\text { menembus } \\
\text { obyek yang } \\
\text { disentuhnya. }\end{array}$ \\
\hline $\begin{array}{l}\text { Direrction } \\
\text { Map }\end{array}$ & $\begin{array}{l}\text { Player } \\
\text { menekan } \\
\text { tombol } \\
\text { direrction } \\
\text { Map yang ada } \\
\text { di main menu. }\end{array}$ & $\begin{array}{l}\text { Berfungsi } \\
\text { dengan baik, } \\
\text { dapat } \\
\text { manampilkan } \\
\text { capture } \\
\text { direction map } \\
\text { Museum Sunan } \\
\text { Drajat. }\end{array}$ \\
\hline Next & $\begin{array}{l}\text { Player } \\
\text { menekan } \\
\text { tombol next } \\
\text { pada scene }\end{array}$ & $\begin{array}{l}\text { Berfungsi } \\
\text { dengan baik, } \\
\text { dapat } \\
\text { menampilkan }\end{array}$ \\
\hline
\end{tabular}

\begin{tabular}{|c|c|c|}
\hline Fitur & $\begin{array}{l}\text { Prosedur } \\
\text { Pengujian }\end{array}$ & Hasil Pengujian \\
\hline & $\begin{array}{l}\text { Direction } \\
\text { map. }\end{array}$ & $\begin{array}{l}\text { capture map } \\
\text { selanjutnya. }\end{array}$ \\
\hline Explore & $\begin{array}{l}\text { Player } \\
\text { menekan } \\
\text { tombol } \\
\text { explore pada } \\
\text { main menu. }\end{array}$ & $\begin{array}{l}\text { Berfungsi } \\
\text { dengan baik, } \\
\text { dapat } \\
\text { menampilkan } \\
\text { suasana ruangan } \\
\text { Museum beserta } \\
\text { koleksi-koleksi } \\
\text { Museum. }\end{array}$ \\
\hline $\begin{array}{l}\text { Lihat } \\
\text { deskripsi } \\
\text { (klik } \\
\text { disini) }\end{array}$ & $\begin{array}{l}\text { Player } \\
\text { menekan } \\
\text { tombol Lihat } \\
\text { deskripsi (klik } \\
\text { disini) pada } \\
\text { scene Museum } \\
\text {. }\end{array}$ & $\begin{array}{l}\text { Berfungsi } \\
\text { dengan baik, } \\
\text { dapat } \\
\text { menampilkan } \\
\text { deskripsi dari } \\
\text { benda-benda } \\
\text { koleksi } \\
\text { museum. }\end{array}$ \\
\hline $\begin{array}{l}\text { Back to } \\
\text { Explore }\end{array}$ & $\begin{array}{l}\text { Player } \\
\text { menekan } \\
\text { tombol back to } \\
\text { explore pada } \\
\text { deskripsi } \\
\text { screen. }\end{array}$ & $\begin{array}{l}\text { Berfungsi } \\
\text { dengan baik, } \\
\text { player dapat } \\
\text { kembali ke } \\
\text { scene Museum } \\
\text { untuk eksplorasi } \\
\text { kembali di } \\
\text { dalam Museum. }\end{array}$ \\
\hline Evaluation & $\begin{array}{l}\text { Player } \\
\text { menekan } \\
\text { tombol } \\
\text { evaluation } \\
\text { pada main } \\
\text { menu }\end{array}$ & $\begin{array}{l}\text { Berfungsi } \\
\text { dengan baik, } \\
\text { dapat } \\
\text { menampilkan } \\
\text { scene } \\
\text { evaluation. } \\
\text { Menampilkan } \\
\text { soal, jawaban, } \\
\text { dan skor. } \\
\end{array}$ \\
\hline Home & $\begin{array}{l}\text { Player } \\
\text { menekan } \\
\text { tombol home. } \\
\text { Tombol home } \\
\text { dapat } \\
\text { ditemukan } \\
\text { ketika kepala } \\
\text { player } \\
\text { menunduk }\end{array}$ & $\begin{array}{l}\text { Berfungsi } \\
\text { dengan baik, } \\
\text { player dapat } \\
\text { kembali ke main } \\
\text { menu. }\end{array}$ \\
\hline Exit & $\begin{array}{l}\text { Player } \\
\text { menekan } \\
\text { tombol exit } \\
\text { pada main } \\
\text { menu. }\end{array}$ & $\begin{array}{l}\text { Berfungsi } \\
\text { dengan baik, } \\
\text { dapat langsung } \\
\text { keluar dari } \\
\text { aplikasi. }\end{array}$ \\
\hline
\end{tabular}

Hasil dari uji fungsionalitas fitur pada aplikasi VR Museum Sunan Drajat tampak pada Tabel 1 dan Tabel 2. Dari data tersebut menunjukkan bahwa semua fitur pada aplikasi ini dapat berfungsi dengan baik. 
Tabel 2 Uji coba aplikasi Virtual Reality Museum Sunan Drajat pada perangkat

\begin{tabular}{|c|c|c|c|}
\hline Perangkat & Spesifikasi & Uji Coba & Hasil \\
\hline $\begin{array}{l}\text { Asus } \\
\text { Zenfone } \\
\text { Selfie } \\
\text { ZD551KL }\end{array}$ & $\begin{array}{l}\text { CPU Octa- } \\
\text { core 4x1.7 } \\
\text { GHz } \\
\text { Cortex- } \\
\text { A53 \& } \\
4 x 1.0 \mathrm{GHz} \\
\text { Cortex- } \\
\text { A53 Layar } \\
1080 \text { x } \\
1920 \\
\text { piksel (5.5 } \\
\text { inch) } \\
\text { RAM } 2 \\
\text { GB } \\
\text { Internal } 16 \\
\text { GB }\end{array}$ & & Baik \\
\hline $\begin{array}{l}\text { Xiaomi } \\
\text { Redmi } \\
\text { Note } 2\end{array}$ & $\begin{array}{l}\text { CPU Octa- } \\
\text { core } 2.0 \\
\text { GHz } \\
\text { Layar } 1920 \\
\text { x } 1080 \\
\text { piksel }(5.5 \\
\text { inch) } \\
\text { RAM } 2 \\
\text { GB } \\
\text { Internal } 16 \\
\text { GB }\end{array}$ & & Baik \\
\hline $\begin{array}{l}\text { Xiaomi } \\
\text { Redmi } \\
\text { Note } 3\end{array}$ & $\begin{array}{l}\text { CPU } \\
\text { Hexa-core } \\
1.4 \mathrm{GHz} \\
\text { Layar } 1080 \\
\text { x } 1920 \\
\text { piksel }(5.5 \\
\text { inch) } \\
\text { RAM } 2 \\
\text { GB } \\
\text { Internal } 16 \\
\text { GB } \\
\end{array}$ & & Baik \\
\hline $\begin{array}{l}\text { Xiaomi } \\
\text { Redmi 4X }\end{array}$ & $\begin{array}{l}\text { CPU Octa- } \\
\text { core } 1.4 \\
\text { GHz } \\
\text { Cortex- } \\
\text { A53 } \\
\text { Layar } 1280 \\
\text { x } 720 \\
\text { piksel (5.0 } \\
\text { inch) } \\
\text { RAM } 2 \\
\text { GB } \\
\text { Internal } 16 \\
\text { GB }\end{array}$ & & Baik \\
\hline $\begin{array}{l}\text { Xiaomi } \\
\text { Redmi } 3\end{array}$ & $\begin{array}{l}\text { CPU Octa- } \\
\text { core } 4 \times 1.5\end{array}$ & & Baik \\
\hline
\end{tabular}

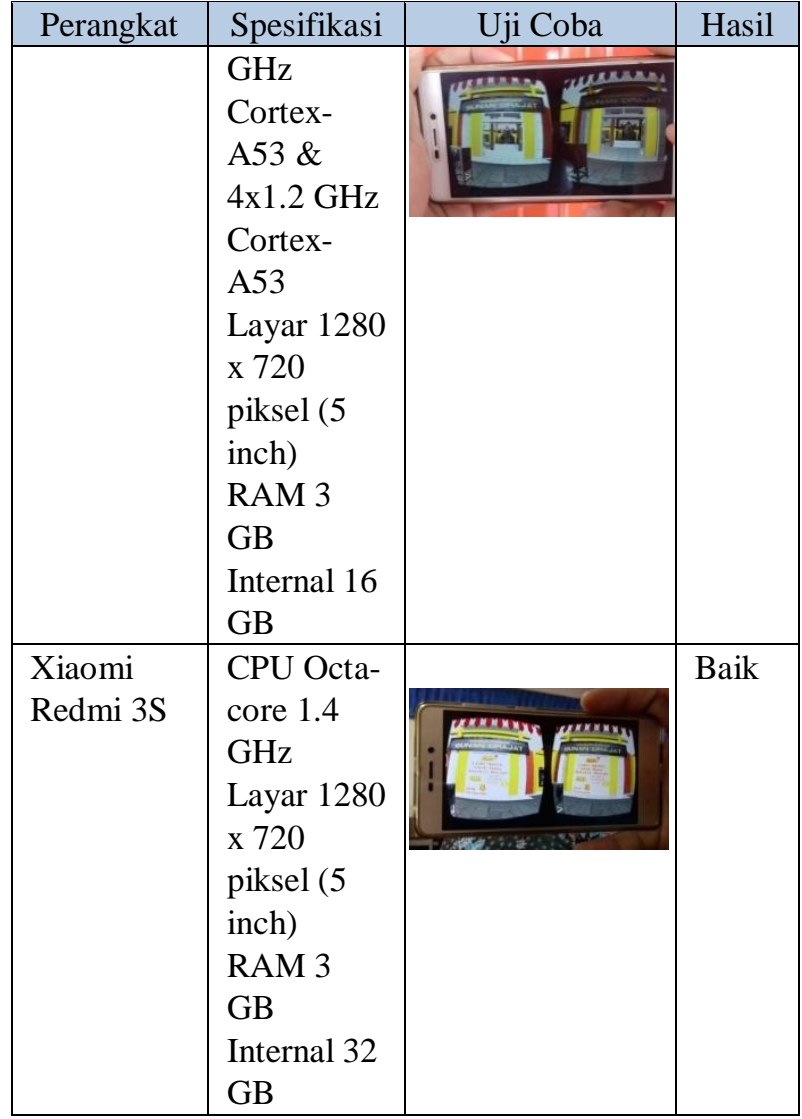

\subsection{Pengujian Kualitas Aplikasi Menggunakan Metode Heuristic Evaluation}

Pada tahap ini dilakukan pengukuran terhadap nilai usability dan fungsionalitas (Kusumaningsih, 2017). Pengujian dilakukan dengan cara menyebarkan kuisioner kepada para Evaluator. Pada penelitian ini yang akan dijadikan sebagai evaluator adalah yang bisa menggunakan Smartphone Android. Evaluator berjumlah 100 orang dengan usia di atas 18 tahun yang sudah pernah berkunjung dan yang belum pernah berkunjung ke museum. Untuk pengujiannya para evaluator menggunakan cardboard yang telah dipasang perangakat Mobile Android, kemudian evaluator akan menjalankan aplikasi dan menganalisa performa dari aplikasi VR Museum Sunan Drajat dengan mengisi kuisioner yang telah disediakan. Pengukuran rating performa terdapat pada Tabel 3.

Tabel 3. Pengukuran rating performa aplikasi Virtual Reality Museum Sunan Drajat

\begin{tabular}{|l|l|c|l|}
\hline NO & $\begin{array}{c}\text { DAFTAR } \\
\text { PERTANYAAN }\end{array}$ & NO & $\begin{array}{c}\text { DAFTAR } \\
\text { PERTANYAAN }\end{array}$ \\
\hline \multicolumn{2}{|c|}{ Usability Test } & \multicolumn{2}{|c|}{$\begin{array}{c}\text { Kesesuaian Obyek 3D } \\
\text { dengan Obyek Real }\end{array}$} \\
\hline 1. & $\begin{array}{l}\text { Apakah aplikasi ini } \\
\text { dapat digunakan } \\
\text { dengan mudah. }\end{array}$ & 1. & $\begin{array}{l}\text { Desain 3D gedung } \\
\text { museum. }\end{array}$ \\
\hline 2. & $\begin{array}{l}\text { Apakah informasi } \\
\text { yang diberikan pada } \\
\text { aplikasi ini mudah } \\
\text { dipahami. }\end{array}$ & 2. & $\begin{array}{l}\text { Tata letak obyek 3D } \\
\text { yang ada di dalam } \\
\text { gedung museum. }\end{array}$ \\
\hline
\end{tabular}




\begin{tabular}{|c|c|c|c|}
\hline NO & $\begin{array}{c}\text { DAFTAR } \\
\text { PERTANYAAN }\end{array}$ & NO & $\begin{array}{c}\text { DAFTAR } \\
\text { PERTANYAAN }\end{array}$ \\
\hline 3. & $\begin{array}{l}\text { Apakah tombol- } \\
\text { tombol pada aplikasi } \\
\text { ini sangat jelas. }\end{array}$ & 3. & $\begin{array}{l}\text { Warna pada obyek } \\
\text { 3D gedung museum }\end{array}$ \\
\hline 4. & $\begin{array}{l}\text { Apakah posisi tombol } \\
\text { pada aplikasi ini } \\
\text { konsisten dan tidak } \\
\text { membingungkan. }\end{array}$ & 4. & $\begin{array}{l}\text { Warna pada obyek } \\
\text { 3D koleksi museum }\end{array}$ \\
\hline 5. & $\begin{array}{l}\text { Apakah mudah } \\
\text { dalam menemukan } \\
\text { tombol home. }\end{array}$ & 5. & $\begin{array}{l}\text { Desain 3D bedhug } \\
\text { yang ada di tengah } \\
\text { gedung museum. }\end{array}$ \\
\hline 6. & $\begin{array}{l}\text { Apakah aplikasi ini } \\
\text { dapat dijadikan } \\
\text { sebagai pembelajaran } \\
\text { sejarah. }\end{array}$ & 6. & $\begin{array}{l}\text { Desain 3D koleksi } \\
\text { museum fragmen } \\
\text { masjid Sendang } \\
\text { Duwur. }\end{array}$ \\
\hline 7. & $\begin{array}{l}\text { Apakah aplikasi ini } \\
\text { nyaman dilihat saat } \\
\text { dipasang pada } \\
\text { cardboard. }\end{array}$ & 7. & $\begin{array}{l}\text { Desain 3D koleksi } \\
\text { museum keramik. }\end{array}$ \\
\hline \multicolumn{2}{|c|}{ Fungsionalitas Test } & 8. & $\begin{array}{l}\text { Desain 3D koleksi } \\
\text { museum alat musik }\end{array}$ \\
\hline 8. & $\begin{array}{l}\text { Apakah semua } \\
\text { tombol sudah sesuai } \\
\text { dengan fungsinya. }\end{array}$ & 9. & $\begin{array}{l}\text { Desain 3D koleksi } \\
\text { museum tombak, } \\
\text { batik drajat, genta } \\
\text { gantung, dan jadhug. }\end{array}$ \\
\hline 9. & $\begin{array}{l}\text { Apakah aplikasi } \\
\text { berjalan dengan baik } \\
\text { tanpa bug. }\end{array}$ & 10. & $\begin{array}{l}\text { Desain 3D koleksi } \\
\text { museum batu, fosil, } \\
\text { gerabah, koin. }\end{array}$ \\
\hline 10. & $\begin{array}{l}\text { Apakah tidak } \\
\text { mengalami lag saat } \\
\text { aplikasi berjalan. }\end{array}$ & 11. & $\begin{array}{l}\text { Desain 3D koleksi } \\
\text { museum naskah } \\
\text { lontar. }\end{array}$ \\
\hline 11. & $\begin{array}{l}\text { Apakah hasil skor } \\
\text { pada menu } \\
\text { evaluation sudah } \\
\text { sesuai. }\end{array}$ & 12. & $\begin{array}{l}\text { Desain 3D koleksi } \\
\text { museum kitab. }\end{array}$ \\
\hline 12. & $\begin{array}{l}\text { Apakah loading pada } \\
\text { aplikasi ini cukup } \\
\text { cepat. }\end{array}$ & 13. & $\begin{array}{l}\text { Desain 3D koleksi } \\
\text { museum pusaka }\end{array}$ \\
\hline
\end{tabular}

Pengukuran menggunakan skala Likert (5 tingkat), yaitu: Sangat Tidak Setuju (STS), Tidak Setuju (TS), Cukup (C), Setuju (S), dan Sangat Setuju (SS). Untuk menghitung hasil dari tiap panel yang dipilih Evaluator, menggunakan formlula $\mathrm{T} \times \mathrm{Pn}$, dengan,

$\mathrm{T}=$ Jumlah tiap panel yang dipilih Evaluator

$\mathrm{Pn}=$ Skala Likert untuk tiap kolom $(\mathrm{SS}=5, \mathrm{~S}=$ $4, \mathrm{C}=3, \mathrm{TS}=2$, STS $=1$ )

Setelah panel yang dipilih untuk masing-masing pertanyaan dijumlah dan dihitung totalnya, maka didapatkan presentase masing-masing pertanyaan dengan perhitungan sebagai berikut:

$\mathrm{Y}=$ (skor tertinggi Likert) $\mathrm{x}$ (Jumlah Evaluator)

$$
\begin{aligned}
& =5 \times 100 \\
& =500
\end{aligned}
$$

Interval $=100 / 5$ skala Likert $=20$

Untuk mendapatkan persentase hasil $=[($ Total tiap pertanyaan / Y) x 100].
Hasil tersebut kemudian diberikan predikat sesuai dengan skala Likert. Rincian hasil tiap pertanyaan sesuai pada Tabel 4 dan Tabel 5.

Tabel 4. Hasil evaluasi berdasarkan usability,

\begin{tabular}{|c|c|c|c|c|c|c|c|c|c|c|c|}
\hline \multirow{3}{*}{$\begin{array}{l}\mathbf{N} \\
\mathbf{o .}\end{array}$} & \multicolumn{5}{|c|}{ JAWABAN } & \multirow{3}{*}{$\begin{array}{l}\mathbf{N} \\
\mathbf{o}\end{array}$} & \multicolumn{5}{|c|}{ JAWABAN } \\
\hline & S & $\mathbf{S}$ & $\mathbf{C}$ & $\begin{array}{l}\mathbf{T} \\
\mathbf{S}\end{array}$ & $\mathbf{S}$ & & SS & $\mathbf{S}$ & $\mathbf{C}$ & $\begin{array}{l}\mathbf{T} \\
\mathbf{S}\end{array}$ & $\begin{array}{l}\mathbf{S} \\
\mathbf{T} \\
\mathbf{S}\end{array}$ \\
\hline & 5 & 4 & 3 & 2 & 1 & & 5 & 4 & 3 & 2 & 1 \\
\hline & \multicolumn{5}{|c|}{ Usability Test } & & \multicolumn{5}{|c|}{$\begin{array}{c}\text { Kesesuaian Obyek 3D } \\
\text { dengan Obyek Real }\end{array}$} \\
\hline 1. & 48 & 44 & 7 & 1 & 0 & 1. & 100 & 0 & 0 & 0 & 0 \\
\hline 2. & 44 & 49 & 6 & 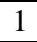 & 0 & 2. & 100 & 0 & 0 & 0 & 0 \\
\hline 3. & 3 & 40 & 7 & & & 3. & 40 & 60 & 0 & & 0 \\
\hline 4. & 15 & 67 & 16 & 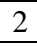 & 0 & 4. & 100 & 0 & 0 & 0 & 0 \\
\hline 5. & 49 & 43 & 7 & 1 & 0 & 5. & 100 & 0 & 0 & 0 & 0 \\
\hline 6. & 57 & 36 & 6 & & 0 & 6. & 100 & 0 & 0 & 0 & 0 \\
\hline \multirow[t]{2}{*}{7.} & 46 & 46 & 7 & 1 & 0 & 7. & 100 & 0 & 0 & 0 & 0 \\
\hline & \multicolumn{5}{|c|}{ Fungsionalitas Test } & 8 & 100 & 0 & 0 & 0 & 0 \\
\hline 8. & 66 & 29 & 5 & 0 & 0 & 9. & 100 & 0 & 0 & 0 & 0 \\
\hline 9. & 51 & 37 & 10 & 2 & 0 & 10. & 100 & 0 & 0 & 0 & 0 \\
\hline 10 & 56 & 28 & 7 & 9 & 0 & 1 & 100 & 0 & 0 & 0 & 0 \\
\hline 11 & 52 & 36 & 12 & 0 & 0 & 12. & 100 & 0 & 0 & 0 & 0 \\
\hline 12 & 12 & 54 & 31 & 3 & 0 & 13. & 100 & 0 & 0 & 0 & 0 \\
\hline
\end{tabular}
fungsionalitas dan kesesuaian desain

Pengujian menggunakan kuisioner menunjukkan hasil persentase kepuasan pengguna berdasarkan usability test, fungsionalitas test dan penilaian kesesuaian obyek 3D dengan obyek real menunjukkan nilai rata-rata yang sangat memuaskan yaitu $89,14 \%, 91 \%$, dan $99 \%$. Hal ini menunjukkan secara umum responden sangat setuju bahwa kualitas aplikasi museum Sunan Drajat ini sangat baik.

\subsection{Evaluasi Keefektifan Aplikasi sebagai Pembelajaran Sejarah}

Pada penelitian ini yang dijadikan sebagai subyek evaluator adalah individu yang sudah familiar dengan smartphone Android. Evaluator berjumlah 10 orang dengan usia di atas 18 tahun yang belum pernah berkunjung dan yang belum pernah berkunjung ke museum.

Pada proses pengujian, para evaluator menggunakan cardboard yang telah dipasang perangkat mobile Android, kemudian evaluator menjalankan aplikasi dan menjelajah museum. Pada menu explore, evaluator tidak hanya sekedar menjelajah namun juga diharuskan mengingat nama dari masing-masing koleksi museum. Kemudian evaluator akan menjalankan menu evaluation untuk menyelesaikan 10 soal yang telah tersedia, skor yang diperoleh evaluator digunakan sebagai ukuran dari penilaian keefektifan aplikasi sebagai pembelajaran 
sejarah. Hasil evaluasi keefektifan aplikasi ditunjukkan pada Tabel 6.

Tabel 5. Hasil evaluasi skala Likert

\begin{tabular}{|c|c|c|c|c|}
\hline \multicolumn{2}{|c|}{ Pengujian } & $\begin{array}{c}\text { Usability } \\
\text { Test }\end{array}$ & $\begin{array}{c}\text { Fungsionalitas } \\
\text { Test }\end{array}$ & $\begin{array}{c}\text { Visualisasi, } \\
\text { Kesesuaian Obyek } \\
\text { 3D dengan Obyek } \\
\text { Real }\end{array}$ \\
\hline & No. & & & \\
\hline \multirow{5}{*}{ Tingkat } & 1 & $82,8 \%$ & - & $100 \%$ \\
\cline { 2 - 5 } & 2 & $87,2 \%$ & - & $100 \%$ \\
\cline { 2 - 5 } & 3 & $89,2 \%$ & - & $92 \%$ \\
\cline { 2 - 5 } & 4 & $93.60 \%$ & - & $100 \%$ \\
\cline { 2 - 5 } & 5 & $88 \%$ & - & $100 \%$ \\
\cline { 2 - 5 } & 6 & $95.80 \%$ & - & $100 \%$ \\
\cline { 2 - 5 } & 7 & $87,4 \%$ & - & $100 \%$ \\
\cline { 2 - 5 } & 8 & - & $99 \%$ & $100 \%$ \\
\cline { 2 - 5 } & 9 & - & $95,8 \%$ & $100 \%$ \\
\cline { 2 - 5 } & 10 & - & $86,2 \%$ & $100 \%$ \\
\cline { 2 - 5 } & 11 & - & $99.40 \%$ & $100 \%$ \\
\cline { 2 - 5 } & 12 & - & $75 \%$ & $100 \%$ \\
\cline { 2 - 5 } & 13 & - & & $100 \%$ \\
\hline
\end{tabular}

Dengan menggunakan skala Interval $=100 / 5$ maka skala Likert yang didapat adalah $=20$.

Sehingga dapat disimpulkan dari hasil uji keefektifan aplikasi VR Museum Sunan Drajat sebagai pembelajaran sejarah memperoleh nilai persentase dapat dihitung sebagai berikut:

Persentase hasil $=[($ Total $/ \mathrm{Y}) \times 100]$

$$
\begin{aligned}
& =[92 / 100) \times 100] \\
& =92 \% \sim \text { Sangat Setuju }(\mathrm{SS})
\end{aligned}
$$

Yang berarti responden sangat setuju (SS) bahwa aplikasi ini efektif digunakan sebagai pembelajaran sejarah.

Tabel 6. Pengujian kefektifan aplikasi sebagai media pembelajaran sejarah

\begin{tabular}{|c|c|c|}
\hline Evaluator & $\begin{array}{c}\text { Jenis } \\
\text { kelamin }\end{array}$ & $\begin{array}{c}\text { Skor yang } \\
\text { diperoleh }\end{array}$ \\
\hline Player 1 & L & 90 \\
\hline Player 2 & L & 100 \\
\hline Player 3 & L & 90 \\
\hline Player 4 & L & 90 \\
\hline Player 5 & L & 90 \\
\hline Player 6 & P & 100 \\
\hline Player 7 & P & 90 \\
\hline Player 8 & P & 90 \\
\hline Player 9 & P & 100 \\
\hline Player 10 & P & 80 \\
\hline \multicolumn{2}{|c|}{ Rata-rata } & 92 \\
\hline \multicolumn{2}{|c|}{}
\end{tabular}

\section{KESIMPULAN}

Dari hasil penelitian yang telah dilakukan, dapat ditarik kesimpulan sebagai berikut:

1. Dari hasil pengujian aplikasi dengan menggunakan metode Heuristic Evaluation didapatkan nilai rata-rata keseluruhan yaitu $93 \%$ yang berarti responden sangat setuju bahwa kualitas aplikasi VR Museum Sunan Drajat sangat baik.

2. Aplikasi VR Museum Sunan Drajat sangat efektif dalam pembelajaran sejarah. Berdasarkan dari nilai evaluasi media pembelajaran didapatkan nilai $92 \%$ sehingga dapat disimpulkan bahwa aplikasi sangat layak dijadikan media pembelajaran sejarah

3. Dari hasil pengujian pada 6 perangkat Andorid dan analisa menunjukkan bahwa aplikasi dapat berjalan baik, spesifikasi minimal dari smartphone yang digunakan yaitu CPU Hexacore $1.4 \mathrm{GHz}$, Layar 1080 x 1920 piksel (5.5 inch), RAM 2 GB, Internal 16 GB.

\section{DAFTAR PUSTAKA}

ANIS, I., 2016. An Overview of Museum Sunan Drajat Story, Desa Drajat, Kecamatan Paciran, Kabupaten Lamongan, Jawa Timur, Indonesia.

ARIF, S.N., 2011. Implementasi Rule-Based Expert Systems dalam Mendeteksi Kerusakan Sistem Jaringan Komputer dengan Metode Backward Chaining, STMIK Triguna Dharma, Medan.

DASTBAZ, M., 2002. Designing Interactive Multimedia Systems, McGraw-Hill, London.

F. HAYES-ROTH, 1985, "Rule-based Systems," Commun. ACM, vol. 28, no. 9, pp. 921932.

KUSUMANINGSIH, A., 2017. User Experience Measurement On Virtual Dressing Room of Madura Batik Clothes, dalam International Conference on Sustainable Information Engineering and Technology, Malang.

NASTITI, F.E., 2016. Perangkat Lunak Bantu Paleontologi Penentuan Usia Fosil Purba Menggunakan Pendekatan Rule Based Architecture, dalam Jurnal Teknologi Informasi dan Komputer, Vol 3, No 3, pp. 156-162.

SIHITE, B., SAMOPA, F., dan SANI, A.S., 2013, Pembuatan Aplikasi 3D Viewer Mobile dengan Menggunakan Teknologi Virtual Reality (Studi Kasus: Perobekan Bendera Belanda di Hotel Majapahit) dalam Jurnal Teknik POMITS, Vol 2, No. 2, pp. 397400.

WOJCIECHOWSKI, R., WALCZAK, K., WHITE, M. dan CELLARY, W., 2004. Building Virtual and Augmented Reality museum Exhibitions, Proceedings Of The Ninth International Conference On 3D Web Technology, pp 135-144. California. 